\title{
What determines the self-rated health of older individuals with stroke compared to other older individuals? A cross-sectional analysis of the Medical Research Council Cognitive Function and Aging Study
}

Nahal Mavaddat ${ }^{1 *}$, Rianne Van der Linde ${ }^{2}$, George M Savva ${ }^{3}$, Carol Brayne ${ }^{2}$ and Jonathan Mant ${ }^{1}$

\begin{abstract}
Background: Poor self-rated health has been associated with poorer objective health outcomes across a range of conditions including stroke. Identification of factors associated with poor self-rated health in stroke survivors has received little attention compared to that in other older individuals. This study identifies determinants of self-rated health in older individuals with or without a history of stroke participating in the population-representative MRC Cognitive Function and Aging Study (MRC CFAS).

Methods: The MRC CFAS is a multicentred longitudinal survey of a population representative sample of people in their 65th year and older at baseline. Baseline interview included questions about functional disability, psychiatric history, independent living status, social interactions, and cognitive function. Multiple logistic regression was used to determine associations between demographic, physical, cognitive, psychological and social factors with poor self-rated health among those with and without stroke.

Results: After excluding those with impaired cognitive function, 776 individuals out of 11,957 reported a stroke. Factors associated with self-rated health were similar between those with or without a stroke in older individuals. Poorer self-rated health in those who had suffered a stroke was associated predominantly with the presence of comorbidity with diabetes (OR 3.5; 95\% Cl 1.5-8.1) and not "getting out and about" (OR 2.6; 95\% Cl 1.7-4.1) even after adjustment for disability levels and for depression. In those without a stroke the most important determinants were disability (OR 3.9; 95\% Cl 3.2-4.8) and not "getting out and about" (OR 2.9; 95\% Cl 2.5-3.3). The presence of disability was less strongly associated with poor self-rated health in those with a history of stroke than those without due to a substantially higher reporting of poor self-rated health in the non-disabled stroke group than the non-disabled stroke-free group, while those with disabilities reported poor self-rated health irrespective of stroke status.

Conclusions: Self-rated health is determined by a range of psychological and social factors in addition to disability in older patients with stroke. Addressing social integration and mobility out of the home is an important element of rehabilitation for older people with stroke as well as those without.
\end{abstract}

Keywords: Stroke self-rated health old age rehabilitation mobility

\footnotetext{
* Correspondence: nm212@medschl.cam.ac.uk

'Department of Public Health and Primary Care, University of Cambridge

Strangeways Laboratory, Worts Causeway, Cambridge CB1 8RN, UK

Full list of author information is available at the end of the article
} 


\section{Background}

As the population in developed nations ages, the burden of stroke, already a cause of considerable disability, [1] is expected to rise [2]. Advances in the management of acute stroke, however, have not been matched by evidence to inform the longer-term support of function, well-being and adaptation of older patients with stroke back into the community $[3,4]$. Severity, type and location of stroke, access to acute medical and nursing care and stroke units, cognitive impairment, lifestyle factors and presence of comorbidities have all been related to long-term outcome after a stroke $[5,6]$. Some evidence however, now suggests a relationship between a stroke survivors' own subjective health and future outcome. It may, therefore be relevant after stroke to incorporate patient-centred assessments to inform rehabilitation strategies [7-9].

Self-rated health (SRH) is an overall subjective assessment of health involving mental, social and physical dimensions, which correlates well with general well-being [10-12]. It is an independent predictor of poor health outcomes across a range of studies even after adjusting for objective biological measures [13-15]. It has also been shown to predict stroke onset and long-term stroke outcome $[9,13]$. Addressing elements of daily life that effect subjective well-being are being increasingly recognised as being important to aiding recovery and adaptation to stroke [16-18]. Determinants of subjective health in the general population and in the elderly have been studied widely $[11,12,19]$. Factors such as marital status, educational level, social class, physical activity, lifestyle, and presence of depression and chronic illness, have all been previously related to self-rated health in elderly populations in differing global settings [20-23]. Few studies, however, have directly compared differences in the factors associated with self-rated health in older populations with stroke to those with no history of stroke. This is potentially important, since understanding self-rated health in stroke survivors can be used to inform rehabilitation services.

The aim of this study is to identify factors that contribute to poor self-rated health in people with stroke in the UK compared with other older individuals in the community. Factors chosen for analysis were those previously related to self-rated health in studies of elderly and normal populations [11,12,19-22]. The study uses data from the MRC Cognitive Function and Aging Study (MRC-CFAS), a study of individuals aged 65 years and over recruited from the community in which physical, psychological, social and cognitive status was determined.

\section{Methods}

The Medical Research Council Cognitive Function and Ageing Study (MRC CFAS) is a multi-centre population based study of individuals aged 65 years and over living in the community, including care homes. The study began in 1991 and was designed to determine the incidence of dementia [24].

The study has six centres across England and Wales chosen to represent the national variation of urban-rural mix, socio-economic deprivation and rates of chronic disease [24]. Five of these centres with identical study designs (Oxford, Nottingham, Newcastle, Cambridgeshire and Gwynedd), are used in the present investigation. The sixth centre (Liverpool) used a different design and is not included. Random samples of people in their 65th year and above were obtained from Family Health Service Authority lists from these five centres. The sample was stratified by age (65-74 years and 75 years and over) and equal numbers were randomly selected from these two age groups with the aim of recruiting 2500 to each centre.

Of those 16258 eligible and available to take part in CFAS, 13004 (80\%) agreed to participate. All study centres obtained ethical approval from local research committees and from the Eastern Multicentre Research Ethics Committee Ref: 05/MRE05/37. Eligible participants (or their proxies where appropriate) provided informed consent. Trained interviewers undertook baseline interviews in the participants' homes.

Socio-demographic factors collected included age, sex, marital status, type of accommodation and social class using the Registrar General's Occupational Classification [25].

The presence of stroke was determined from self-report through the question: "Have you ever had a stroke that required medical attention?" Time since stroke was determined by subtracting the response to the question: "How old were you when you had the last stroke?" from age at data collection.

General subjective health status or self-rated health (SRH) was determined with the question: "Would you say that for someone of your age, your own health in general is" followed by a list of options from poor to excellent.

Participants were asked about health behaviours including smoking status and alcohol intake. Comorbidities were assessed by the questions: "Have you ever suffered from high blood pressure, angina, heart attack, diabetes or head-injury"?

Functional status was determined by enquiring about activities of daily living (ADL) and instrumental activities of daily living (IADL). ADL disability was defined as requiring help at least several times per week with activities of daily living such as washing, cooking, dressing, or if the respondent was housebound. IADL disability was defined as needing help with heavy housework or shopping and carrying heavy bags.

Cognitive status was determined using the Mini Mental State Examination [26] and the Verbal Fluency Test [27].

History of depression was determined by asking the following questions: "Have you ever consulted a doctor about 
Table 1 Distribution of demographic variables in those with and without stroke in the population of England and Wales aged 65 years and older

\begin{tabular}{|c|c|c|c|c|c|}
\hline & \multicolumn{2}{|c|}{$\begin{array}{l}\text { Individuals } \\
\text { with stroke }\end{array}$} & \multicolumn{2}{|c|}{$\begin{array}{c}\text { Individuals } \\
\text { without stroke }\end{array}$} & \multirow[t]{2}{*}{ P-value ${ }^{\dagger}$} \\
\hline & N & $\%^{*}$ & $\mathrm{~N}$ & $\%^{*}$ & \\
\hline All & 776 & 6.2 & 11,181 & 93.8 & \\
\hline \multicolumn{6}{|l|}{ Gender } \\
\hline Females & 400 & 50.6 & 6,674 & 59.0 & \\
\hline Males & 376 & 49.4 & 4,507 & 41.0 & $<0.01$ \\
\hline \multicolumn{6}{|l|}{ Age mean } \\
\hline Mean & 76.2 & 6.6 & 74.7 & 6.6 & \\
\hline \multicolumn{6}{|l|}{ Age group } \\
\hline $64-74$ & 312 & 48.8 & 5,861 & 60.9 & \\
\hline $75-84$ & 375 & 41.4 & 4,339 & 31.9 & $<0.01$ \\
\hline $85+$ & 89 & 9.8 & 981 & 7.2 & $<0.01$ \\
\hline \multicolumn{6}{|c|}{ Marital Status categorical } \\
\hline Married \& Cohabiting & 396 & 52.8 & 5,782 & 53.9 & \\
\hline Single & 47 & 6.0 & 905 & 7.9 & \\
\hline Widowed & 293 & 35.5 & 4,079 & 34.2 & \\
\hline Divorced/separated & 40 & 5.7 & 414 & 4.0 & \\
\hline \multicolumn{6}{|c|}{ Type of Accommodation ${ }^{\ddagger}$} \\
\hline Independent & 741 & 96.0 & 11,006 & 98.7 & \\
\hline Institutionalised & 35 & 4.1 & 172 & 1.3 & $<0.01$ \\
\hline \multicolumn{6}{|l|}{ Social Class } \\
\hline I Professional & 27 & 3.6 & 544 & 5.0 & $<0.01$ \\
\hline |l Managerial & 179 & 23.7 & 2,892 & 26.5 & \\
\hline Illa Skilled (non-manual) & 85 & 11.2 & 1,287 & 11.7 & \\
\hline Illb Skilled (manual) & 279 & 36.9 & 4,076 & 37.6 & \\
\hline IV Partly skilled & 131 & 17.7 & 1,606 & 14.7 & \\
\hline V Unskilled & 53 & 7.0 & 499 & 4.6 & \\
\hline \multicolumn{6}{|l|}{ Smoking } \\
\hline Never smoked & 216 & 26.7 & 3,817 & 33.2 & \\
\hline Current smoker & 396 & 51.6 & 5,251 & 47.2 & 0.01 \\
\hline Former smoker & 162 & 21.7 & 2,091 & 19.6 & $<0.01$ \\
\hline \multicolumn{6}{|l|}{ Alcohol intake } \\
\hline Never alcohol & 98 & 11.6 & 1,247 & 10.7 & \\
\hline Ever alcohol & 676 & 88.4 & 9,911 & 89.3 & 0.16 \\
\hline \multicolumn{6}{|l|}{ Co-morbidities } \\
\hline High Blood Pressure & 402 & 52.9 & 3,530 & 31.8 & $<0.01$ \\
\hline Angina & 164 & 20.8 & 1,476 & 13.0 & $<0.01$ \\
\hline Heart Attack & 149 & 19.1 & 1,093 & 9.7 & $<0.01$ \\
\hline Diabetes & 70 & 9.2 & 633 & 5.5 & $<0.01$ \\
\hline Head Injury & 112 & 14.6 & 1,254 & 11.4 & $<0.01$ \\
\hline
\end{tabular}

Table 1 Distribution of demographic variables in those with and without stroke in the population of England and Wales aged 65 years and older (Continued)

Time since stroke

$\begin{array}{lcccc}<1 \text { year } & 71 & 9.2 & \text { N/A } & \text { N/A } \\ 1 \text {-2 years } & 185 & 24.6 & \text { N/A } & \text { N/A } \\ \text { 3-5 years } & 179 & 23.4 & \text { N/A } & \text { N/A } \\ >5 \text { years } & 223 & 42.8 & \text { N/A } & \text { N/A }\end{array}$

*percentages backweighted to normal population.

tadjusted for age and sex.

Findependent - House/Flat/Granny flat, Warden Controlled flat , Institution -

Council \&Private, Residential home, Nursing Home, Long Hospital Stay.

emotional problems, or problems with your nerves?" followed by "What did the doctor say you had?"

Social variables were assessed by questions including: "Does anyone else live here?"

"How often do you see any of your (children or other) relatives to speak to?", "Do you have friends in this community?", "How often do you see any of your neighbours to have a chat or do something with?", "Do you attend meetings of any community or church or social groups, such as over 60's clubs, evening classes or anything like that?", and "In general, do you get out and about as much as you would like to?"

\section{Analysis}

All analyses were performed using Stata 12.0. Any participants who had missing data regarding presence of stroke or SRH or had an MMSE that was missing or less than 18 (as their responses could not be considered reliable for the purposes of this analysis), were excluded from the analyses. The distribution at baseline of demographic, physical, psychological, cognitive and social characteristics were described for participants with and without stroke.

For purposes of logistic regression SRH was initially dichotomised into two groups (good $=$ excellent $/$ good vs. poor $=$ fair/poor). The association between each potential predictor and SRH was assessed using multiple logistic regression. Ordinal and linear regression models were considered in order to increase the power of the analysis, however Brant tests following ordinal logistic regression showed that the proportional odds model was strongly violated by this data (suggesting that linear/ ordinal models were not appropriate), although findings based on the linear and logistic models were rarely qualitatively different. Further inspection using different possible cut-points for the dichotomisation of SRH showed that where there were discrepancies between the linear and logistic models, effects were more consistent between the excellent/good vs fair/poor cut-off and the excellent/ good/fair vs poor cut off. Either of these dichotomisations 
Table 2 Distribution of physical, psychological, cognitive and social variables in those with and without stroke in the population of England and Wales aged 65 years and older (Data are count (\%) unless otherwise stated)

\begin{tabular}{|c|c|c|c|c|}
\hline & \multicolumn{2}{|c|}{$\begin{array}{c}\text { Individuals } \\
\text { with stroke } \\
(\mathrm{N}=776)\end{array}$} & \multicolumn{2}{|c|}{$\begin{array}{c}\text { Individuals } \\
\text { without stroke } \\
(\mathrm{N}=11,181)\end{array}$} \\
\hline & N & $\%^{*}$ & N & $\% *$ \\
\hline \multicolumn{5}{|l|}{ Physical } \\
\hline \multicolumn{5}{|l|}{ Disabilities } \\
\hline None & 333 & 44.9 & 8,305 & 76.4 \\
\hline IADL & 130 & 16.4 & 1,557 & 13.2 \\
\hline$A D L$ & 311 & 38.8 & 1,292 & 10.4 \\
\hline \multicolumn{5}{|l|}{ Self-rated Health } \\
\hline Excellent & 59 & 7.5 & 2,349 & 21.3 \\
\hline Good & 280 & 36.0 & 5,535 & 49.7 \\
\hline Fair & 319 & 40.9 & 2,774 & 24.4 \\
\hline Poor & 118 & 15.6 & 523 & 4.7 \\
\hline \multicolumn{5}{|l|}{ Psychological } \\
\hline \multicolumn{5}{|l|}{ Depression/Nerves } \\
\hline No problems & 615 & 78.4 & 8,964 & 79.3 \\
\hline Depression diagnosed & 88 & 12.0 & 980 & 9.1 \\
\hline Other diagnosed & 70 & 9.4 & 1,205 & 11.3 \\
\hline Not diagnosed, sounds like depression & 1 & 0.1 & 18 & 0.2 \\
\hline Not diagnosed, sounds like anxiety & 0 & 0 & 6 & 0.05 \\
\hline Not diagnosed, other & 1 & 0.1 & 3 & 0.03 \\
\hline \multicolumn{5}{|l|}{ Depression diagnosis } \\
\hline No & 687 & 88.0 & 10,196 & 90.9 \\
\hline Yes & 88 & 12.0 & 980 & 9.1 \\
\hline \multicolumn{5}{|l|}{ Cognition } \\
\hline \multicolumn{5}{|l|}{ MMSE } \\
\hline $26-30$ & 389 & 52.4 & 7,559 & 69.4 \\
\hline $22-25$ & 272 & 33.6 & 2,788 & 23.8 \\
\hline $18-21$ & 115 & 14.1 & 834 & 6.8 \\
\hline Verbal Fluency (mean; s.d.) & 13.9 & 5.1 & 16.0 & 5.4 \\
\hline \multicolumn{5}{|l|}{ Social } \\
\hline \multicolumn{5}{|l|}{ Lives alone $\mathrm{e}^{\ddagger}$} \\
\hline With others & 468 & 64.5 & 6,688 & 62.6 \\
\hline Alone & 272 & 35.5 & 4,315 & 37.4 \\
\hline \multicolumn{5}{|l|}{ Sees children and relatives ${ }^{\ddagger}$} \\
\hline Never & 12 & 2.1 & 109 & 1.3 \\
\hline Daily & 160 & 26.1 & 2,290 & 27.2 \\
\hline 2-3 times a week & 142 & 23.1 & 1,982 & 23.4 \\
\hline At least weekly & 157 & 25.9 & 2,099 & 24.7 \\
\hline At least monthly & 67 & 11.4 & 1,043 & 12.3 \\
\hline Less often & 70 & 11.3 & 971 & 11.3 \\
\hline
\end{tabular}

Table 2 Distribution of physical, psychological, cognitive and social variables in those with and without stroke in the population of England and Wales aged 65 years and older (Data are count (\%) unless otherwise stated)

(Continued)

\begin{tabular}{|c|c|c|c|c|}
\hline \multicolumn{5}{|l|}{ Sees neighbours ${ }^{\ddagger}$} \\
\hline Never & 33 & 5.4 & 299 & 3.3 \\
\hline Daily & 236 & 39.5 & 3,972 & 45.3 \\
\hline 2-3 times a week & 173 & 28.8 & 2,391 & 27.3 \\
\hline At least weekly & 87 & 14.5 & 1,379 & 15.7 \\
\hline At least monthly & 36 & 6.0 & 399 & 4.5 \\
\hline Less often & 36 & 5.8 & 341 & 3.8 \\
\hline \multicolumn{5}{|l|}{ Has friends ${ }^{\ddagger}$} \\
\hline Yes & 467 & 74.8 & 7,302 & 81.9 \\
\hline No & 161 & 25.2 & 1,630 & 18.1 \\
\hline \multicolumn{5}{|c|}{ Attends meetings ${ }^{\ddagger}$} \\
\hline Yes, regularly & 232 & 37.4 & 3,951 & 44.7 \\
\hline Yes, occasionally & 51 & 8.4 & 648 & 7.3 \\
\hline None & 330 & 54.2 & 4,296 & 48.1 \\
\hline \multicolumn{5}{|c|}{ Out and about as much as would like } \\
\hline Yes & 362 & 48.7 & 8,223 & 75.2 \\
\hline No & 398 & 51.3 & 2,908 & 24.8 \\
\hline
\end{tabular}

would be reasonable choices for estimating the determinants of self-rated health. When using the excellent vs good/fair/poor cut-off, however, estimates of the effects of potential predictors were different in these cases, and may have driven the difference in the linear model. Since we are not concerned with identifying predictors of excellent as opposed to good SRH, logistic regression using the initial cut-point was finally selected as the most robust and informative analysis.

Potential predictors of SRH were defined as follows: Psychosocial variables included age group (65-74, 7584 , and $85+$ ), gender, social class (divided into manual (IIIb, IV, V) and non-manual (I, II, IIIa)), disability (in three groups: no impairment, impairment of IADL only, impairment of ADL), cognition (MMSE divided into four groups, less than 18 or missing, $18-21,22-25$ and $26-30$ ), time since stroke ( $<1$ year, $1-2,3-5$ and $>5$ years), and presence of depression (yes or no). Prevalence estimates were weighted to adjust for oversampling in the study population of those over 75. Differences in characteristics between participants with and without stroke were calculated using logistic regression adjusting for age and sex.

A multivariate logistic regression model adjusting for demographic, physical, psychological, cognitive and social 
factors was constructed to explore the association of SRH with stroke. The associations of these factors with SRH in those with and without stroke were then calculated using univariate and multivariate logistic regression. The statistical significance of the differences in the associations between the covariates and SRH for those with stroke compared to those without stroke were calculated by estimating a final logistic regression model for SRH using data from the whole sample and including each covariate and the interaction of each with stroke as independent variables.

\section{Results}

Of 13,004 participants, 1,047 (8.0\%) of participants were excluded. These were because participants had one or more of a combination of: no information about stroke history $(n=138)$ or because their MMSE was less than 18 or missing $(\mathrm{n}=889)$ or they had missing SRH $(\mathrm{n}=381)$. This left 11,957 eligible of whom 11,181 (93.8\%) had no history of stroke and 776 (6.2\%) who had one or more previous strokes.

Tables 1 and 2 show the frequency of basic demographic, physical, psychological and cognitive profile of older participants reporting a stroke compared to those without a history of stroke. Participants with stroke were older and more likely to be male. After adjusting for age and sex, there were significant differences between people with a history of stroke and those without with regard to several demographic, clinical and psychosocial variables. In particular, there were marked differences in ability to get out and about as much as desired between the two groups, as well as a greater number of people with a history of stroke being depressed and having no friends, and less having contact with neighbours and attending community meetings. More people with a history of stroke reported poor SRH (56.5\%) than those without (29.1\%). The adjusted odds of having poor
SRH in the presence of a history of stroke was over three times (OR 3.1(2.7-3.6)) that in those without a history of stroke.

Table 3 shows the frequency of physical, psychological and cognitive variables by time since self-reported stroke. Physical disability in the form of ADL and IADL impairment was common in the CFAS population in participants with stroke and persisted: Over half of those who had suffered a stroke more than five years previously reported disability compared to less than a quarter of participants without stroke.

An additional online table (Additional file 1: Table S1) shows the prevalence and univariate odds ratios whilst Table 4 shows the fully adjusted odds ratios for the effect on 'poor' compared to 'good' SRH of each factor. The strongest associations of poor SRH in people with stroke were diabetes and "not getting out and about" as much as they wanted. The presence of depression, disabilities and being of lower social class were also significantly independently associated with poor SRH in those with a history of stroke. In people without stroke, the presence of disabilities and "not getting out and about" as much as they wanted were the strongest predictors of poor SRH. Older age was associated with better SRH in both groups.

Several of the predictors of poor SRH applied to both people with and without stroke. However, there were some differences in magnitude between the two groups. While ADL disability was associated with poor SRH in both those with and without stroke, this association was twice as strong in those without stroke $(\mathrm{OR}=3.9 ; 95 \%$ $\mathrm{CI}=3.2-4.1$ in those without stroke compared to $\mathrm{OR}=2.0$; 95\% $\mathrm{CI}=1.2-3.4$ in those with stroke). An investigation of the marginal effects (the modelled probabilities of poor SRH by disability and stroke after adjusting for all other covariates) indicates what underlies this difference (Figure 1). In those with stroke, there was a greater

Table 3 Distribution of selected variables by time since the event in people with stroke in the population of England and Wales aged 65 years and older

\begin{tabular}{|c|c|c|c|c|c|c|c|c|}
\hline & \multicolumn{8}{|c|}{ Years since stroke } \\
\hline & \multicolumn{2}{|c|}{$<1$} & \multicolumn{2}{|c|}{$1-2$} & \multicolumn{2}{|c|}{ 3-5 } & \multicolumn{2}{|c|}{$>5$} \\
\hline & N & $\%^{*}$ & N & $\%^{*}$ & N & $\%^{*}$ & N & $\%^{*}$ \\
\hline Disability (IADL or ADL) & 34 & 47.0 & 108 & 57.3 & 97 & 51.4 & 189 & 56.8 \\
\hline Depression & 7 & 11.1 & 26 & 15.1 & 25 & 14.8 & 28 & 9.0 \\
\hline Living alone & 24 & 34.0 & 69 & 38.4 & 65 & 36.1 & 104 & 32.6 \\
\hline Seeing relatives less than weekly & 15 & 24.9 & 38 & 28.2 & 36 & 25.0 & 56 & 22.7 \\
\hline Seeing neighbours less than weekly & 5 & 8.6 & 33 & 24.8 & 23 & 15.3 & 40 & 15.9 \\
\hline No friends & 11 & 17.5 & 38 & 26.6 & 46 & 29.4 & 62 & 23.5 \\
\hline Not attending meetings & 28 & 48.4 & 71 & 50.8 & 85 & 56.0 & 140 & 56.9 \\
\hline Not out and about as much as would like to be & 38 & 54.9 & 101 & 54.4 & 94 & 51.3 & 154 & 48.2 \\
\hline
\end{tabular}

*percentages backweighted to normal population. 
Table 4 Independent effects of physical, psychological, cognitive and social variables on reporting of poor or fair SRH compared to good or excellent SRH among those with and without stroke in the population of England and Wales aged 65 years and older*

\begin{tabular}{ccccccc}
\hline & \multicolumn{2}{c}{ Individuals } & with stroke & \multicolumn{2}{c}{ Individuals without stroke $^{2}$} & \multicolumn{2}{c}{ Stroke: no stroke $^{\dagger}$} \\
\hline & OR & $95 \% \mathrm{Cl}$ & OR & $95 \% \mathrm{Cl}$ & OR & $95 \% \mathrm{Cl}$
\end{tabular}

Socio-demographic

Sex

Male vs Female

Age group

64-74

75-84

\section{Marital status}

Not married vs currently married

Health behaviour

\section{Smoking}

Never smoked

Former smoker

Current smoker

Alcohol drinker

Ever $v$ Never

Co-morbidities

High Blood Pressure

Yes

Angina

Yes

\section{Heart Attack}

Yes

Diabetes

Yes

Head injury

Yes

Physical

Time since stroke
$<1$ year
1-2 years
3-5 years
$>5$ years

0.7-2.0

\section{Disabilities}

Not disabled

IADL

Ref.

ADL 


\begin{tabular}{|c|c|c|c|c|c|c|}
\hline \multicolumn{7}{|l|}{ Depression diagnosis } \\
\hline Yes & 2.0 & $1.0-3.8$ & 1.6 & $1.4-1.9$ & 1.2 & $0.6-2.4$ \\
\hline \multicolumn{7}{|l|}{ Cognition } \\
\hline \multicolumn{7}{|l|}{ MMSE } \\
\hline $26-30$ & 1.0 & Ref. & 1.0 & Ref. & & \\
\hline $22-25$ & 1.2 & $0.8-2.0$ & 1.0 & $0.9-1.2$ & 1.2 & $0.7-2.0$ \\
\hline $18-21$ & 1.5 & $0.8-3.0$ & 1.0 & $0.8-1.3$ & 1.5 & $0.7-3.0$ \\
\hline \multicolumn{7}{|l|}{ Verbal Fluency } \\
\hline Per 1 animal named less & 1.1 & $1.0-1.1$ & 1.0 & $1.0-1.1$ & 1.0 & $1.0-1.1$ \\
\hline \multicolumn{7}{|l|}{ Social } \\
\hline \multicolumn{7}{|l|}{ Lives alone $^{\neq}$} \\
\hline Alone vs living witgh others & 1.4 & $0.7-2.5$ & 1.1 & $0.9-1.3$ & 1.3 & $0.7-2.4$ \\
\hline \multicolumn{7}{|l|}{ Sees children and relatives ${ }^{\ddagger}$} \\
\hline Less than weekly vs weekly or more & 1.3 & $0.8-2.1$ & 1.1 & $0.9-1.2$ & 1.2 & $0.7-2.0$ \\
\hline \multicolumn{7}{|l|}{ Sees neighbours ${ }^{\ddagger}$} \\
\hline Less than weekly vs weekly or more & 0.7 & $0.4-1.2$ & 0.9 & $0.8-1.1$ & 0.8 & $0.4-1.3$ \\
\hline \multicolumn{7}{|l|}{ Has friends ${ }^{\ddagger}$} \\
\hline No & 1.1 & $0.7-1.9$ & 1.3 & $1.2-1.6$ & 0.8 & $0.5-1.4$ \\
\hline \multicolumn{7}{|l|}{ Attends meetings $^{\ddagger}$} \\
\hline None & 1.0 & Ref. & 1.0 & Ref. & & \\
\hline Yes, occasionally & 0.4 & $0.2-1.0$ & 0.9 & $0.7-1.1$ & 0.5 & $0.2-1.1$ \\
\hline Yes, frequently & 1.0 & $0.6-1.5$ & 0.9 & $0.8-1.0$ & 1.1 & $0.7-1.7$ \\
\hline \multicolumn{7}{|c|}{ Out and about as much as would like ${ }^{\ddagger}$} \\
\hline No & 2.6 & 1.7-4.1 & 2.9 & $2.5-3.3$ & 0.9 & $0.6-1.5$ \\
\hline
\end{tabular}

*odds ratios and $95 \%$ Cl's estimated by multiple logistic regression adjusted for all other variables in the model.

${ }^{+}$interaction of each independent variable with stroke (i.e. ratio between the effects among those with and without stroke). Statistically significant effects and interactions at $p<0.05$ are in bold.

${ }^{\ddagger}$ Social variables missing for approximately $20 \%$ of participants.

probability of reporting poor self-rated health regardless of disability level, such that people with stroke who were not disabled had a much higher probability of reporting poor self-rated health than those without stroke who were not disabled. At the more severely disabled level with ADL impairment, the presence of a stroke made little difference to levels of self-rated health. Angina, high blood pressure and previous heart attack were also more strongly associated with poor SRH in those without stroke than in those with stroke, but the differences as indicated by the interaction terms were not statistically significant. Alcohol consumption, on the other hand, was associated with poorer SRH in people with stroke, and with better SRH in those without stroke. Diabetes had a stronger effect on those with stroke $(\mathrm{OR}=3.5 ; 95 \%$ $\mathrm{CI}=3.2-4.8)$ than those without (OR=1.7; 95\% CI: 1.3-2.1), although again the difference between the groups was not statistically significant.

\section{Discussion}

This study of factors associated with self-rated health in individuals with stroke over 65 compared to other older individuals in the population confirms that self-rated health is determined by a broad range of factors - demographic, physical, social and psychological - and suggests that these are similar in older people with or without a history of stroke. 'Not getting out and about' and the presence of disability or impairments of daily living were strongly associated with poor self-rated health in both those with and without a history of stroke. The association of poor self-rated health with disability was however significantly greater in people without stroke. In both those with and without a stroke, older age was associated with better comparative self-rated health, and the presence of comorbidities with poorer subjective health. The strong association between diabetes and poor selfrated health in those with stroke, of particular importance 


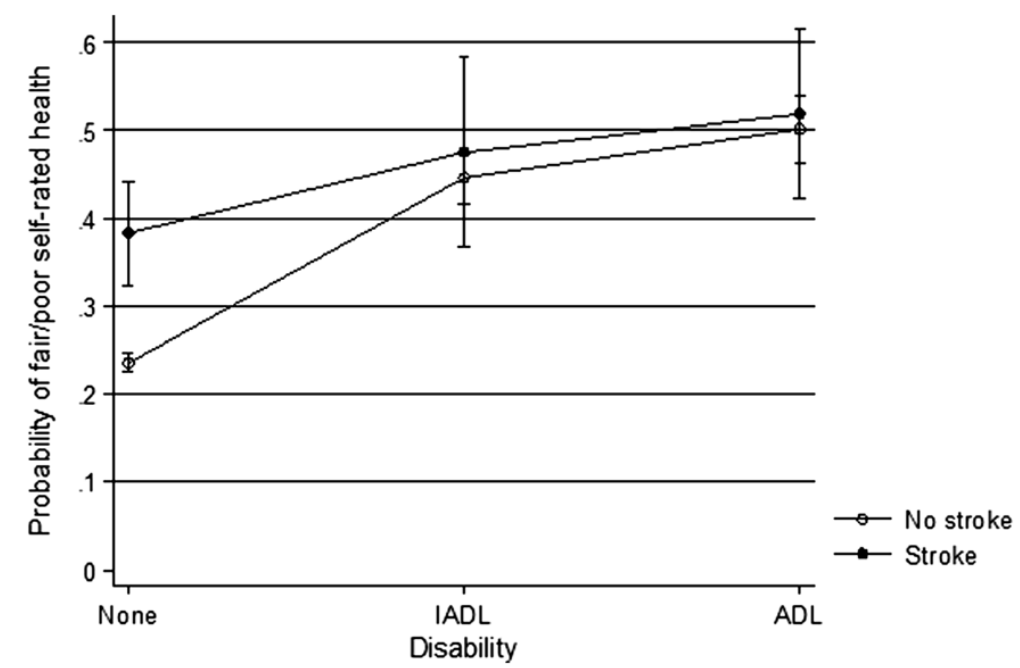

Figure 1 SRH by disability. Interaction plot showing the modelled probability of reporting fair or poor self-rated health in those with no disability, IADL or ADL limitations stratified by stroke status. Estimates are standardised for all covariates in the regression model shown in Table 4, and are presented with 95\% confidence intervals.

in the context of rising rates of comorbidity between diabetes and stroke [28], could relate to the additional difficulties in self-care with diabetes that may arise in the context of physical and cognitive impairments associated with having suffered a stroke. For example, the potential need to self-administer insulin in the face of physical disability, the increased cognitive demands of taking multiple medications, the reduced ability to participate in physical activity, and greater difficulty in accessing medical care and specialised diabetes clinics, may all contribute to worsened diabetic control and potentially subjective health in those with stroke. The presence of diabetes and stroke in combination has been previously shown to be strongly associated with a higher risk of disabilities, poor subjective health and mortality in elderly populations [29]. Other studies suggest that diabetes in association with other chronic medical conditions reduces health-related quality of life in an additive fashion [30]. Depression and being of manual social class, both associated with self-rated health in the general population $[31,32]$ and with poorer functional recovery from stroke [33-36] were also strongly related to poor self-rated health in older individuals, with or without a history of stroke.

Degrees of physical functional impairment or disability have previously been reported as one of the strongest factors associated with poor self-rated health in the general and older population and in patients with stroke $[9,12]$. In our study, however, the presence of physical disability was less strongly associated with poor self-rated health in those with a history of stroke than those without. This is due to a substantially higher rate of reporting of poor self-rated health in the non-disabled stroke group than the non-disabled stroke-free group, while those with
ADL or IADL limitations report poor SRH irrespective of stroke status. Literature on the association of disability with self-rated health suggests that those with chronic disabilities may place greater emphasis on factors other than their physical functioning when reporting self-rated health [37]. Indeed in patients with stroke, other factors were associated more strongly with poor self-rated health than physical disability. For example, the presence of depression in patients with stroke, independent of physical disability and any cognitive impairment, was as strongly associated with poor self-rated health as disability levels, confirming suggestions from other studies that depression may be of equal or even greater importance than physical disability as a predictor of subjective wellbeing and quality of life after stroke $[18,38]$.

An important finding of our study was that poor selfrated health independent of the presence of functional disability and depression, in both those with and without stroke, was strongly associated with a negative response to the question of whether participants were "getting out and about" as much as they would like to. However, in our study no statistically significant independent association between self-rated health was found with more objective social factors such as living alone, or having friends or seeing neighbours. It is likely that the way individuals respond to the "out and about" question reflects to some degree levels of perceived satisfaction with social isolation or interaction. More than five years after a stroke, nearly half of older people with a history of stroke in the CFAS study felt they were not getting out and about as much as they would like to compared with one quarter of those who had never had a stroke. At one to two years after stroke, one of the peak times for social isolation according to our study, a 
quarter of patients with stroke were seeing neighbours less than weekly compared to just over ten percent of those without, and over a quarter had no friends although there was no difference in amount of family contact between those with and without stroke.

The role of social isolation and its converse, participation in social activities and presence of social support and networks is being increasingly confirmed as being an independent factor in stroke outcomes. A number of studies suggest that social dimensions may be of central importance to health related quality of life and physical recovery from stroke [39-42]. However, not "getting out and about" may be influenced by factors other than lack of physical mobility, depression and social interaction, and may reflect to some degree internal qualities such as confidence, motivation and expectations of recovery either positive or negative $[43,44]$. Trials such as the "Getting Out Of The House" study [44] and the "Out and About" trial [45] focussing on outdoor mobility designed to help patients to get out of the house after stroke are therefore particularly pertinent. Such trials aim to assess ways of assisting the individual to spend more time outside the home such as by helping to overcome patients' personal barriers to leaving the house, as well as setting mobility goals and delivering interventions such as practicing driving with patients, or helping them to use the bus or to walk local routes [44]. Our findings suggest that similar initiatives might have promise if applied to older individuals in the population more generally. Any attempts at improving accessibility and friendliness of the local environment such as improvements in local transportation and shop access should also aid the older population and those with disabilities to "get out and about", potentially improving their quality of life and subjective health.

\section{Strengths and limitations of the study}

This study has several strengths including the large size of the cohort of older participants studied with a history stroke, as well as the comparisons made with a large control group of other older people in the community without stroke. Most long-term studies of patients after stroke have either not compared findings with control groups or have used comparison with population norms [3]. Our study reported findings by time since stroke and addressed the impact of time after a stroke with self-rated health, an advantage since most studies of post-stroke patients lack control for duration of stroke onset $[41,46]$. The limitations of the study include data being collected retrospectively and dependent upon self-report in an older population. Although more contemporary than other studies, the CFAS was carried out in the 1990s and changes in disease patterns, treatments and outcomes may have occurred since then. The study was cross-sectional, so a causal relationship between poor self-rated health and associated factors cannot be concluded. For example, not getting out of the house may lead to poorer self-rated health, but it may be that poor self-rated health may lead to decreased likelihood of getting out of the house. As with all observational studies, there is the risk that our associations are confounded by further variables that were not included. For example, 'frailty' was not taken into account, and it is plausible that this has further independent effects that were not adjusted for in our model (which included adjustment for activities of daily living, but not frailty per se).

\section{Conclusions}

In conclusion, our findings emphasise the need to attend to psychosocial aspects of wellbeing as well as addressing physical functioning in both people who have had stroke and those who have not. This reinforces the suggestion that many different types of interventions involving multidisciplinary care may be required to effectively rehabilitate patients with stroke $[18,47,48]$. In particular, efforts at improving subjective wellbeing should include attempts at social reintegration of patients after stroke into the community and getting patients "out and about".

\section{Additional file}

Additional file 1: Table S1. Online Table: Prevalence and univariate odds ratios for poor/fair self-rated health by studied variables in the population of England and Wales aged 65 years and older with or without stroke*.

\section{Competing interests}

All authors declared that they have no competing interests.

\section{Authors' contributions}

CB is Principal Investigator of the MRC CFAS Study. NM, RV and GS contributed to analysis of data. All authors contributed to study design and intellectual input. All authors read and approved the final manuscript.

\section{Authors' information}

CB is Professor of Public Health, JM is Professor of Primary Care Research and NM is Clinical Lecturer in Primary Care Research at the University of Cambridge. GS is Senior Lecturer in Nursing Sciences at the University of East Anglia. RV is currently a PhD student at the University of Cambridge.

\section{Acknowledgements}

We would like to thank all participants and investigators of the MRC Cognitive Function and Ageing Study. We are also grateful to all respondents, their families and their primary care teams from across the country for their participation in the CFAS. The MRC CFAS is funded by the Medical Research Council (grant number G9901400) and Department of Health. NM was funded by a National Institute for Health Research (NIHR) Walport Clinical Lectureship in Primary Care Research. None of the sponsors influenced the design or conduct of the study or the analysis or interpretation of the findings.

\section{Author details}

${ }^{1}$ Department of Public Health and Primary Care, University of Cambridge Strangeways Laboratory, Worts Causeway, Cambridge CB1 8RN, UK. ${ }^{2}$ Department of Public Health and Primary Care, University of Cambridge Forvie Site, Robinson Way, Cambridge CB2 OSR, UK. ${ }^{3}$ School of Nursing Sciences, University of East Anglia Norwich Research Park, Norwich NR4 7TJ, UK. 
Received: 11 October 2012 Accepted: 12 August 2013

Published: 22 August 2013

\section{References}

1. World Health Organization: WHO STEPS Stroke Manual: The WHO STEPwise Approach to Stroke Surveillance. Geneva: WHO; 2006.

2. World Health Organization: The world health report 2000. Geneva: WHO; 2000

3. Patel MD, Tilling K, Lawrence E, Rudd AG, Wolfe CD, McKevitt C: Relationships between long-term stroke disability, handicap and health-related quality of life. Age Ageing 2006, 35:273-279.

4. Young J, Murray JFA: Review of longer-term problems after disabling stroke. Reviews in Clinical Gerontology 2003, 13:55-65.

5. Eriksson M, Norrving B, Terent A, Stegmayr B: Functional outcome 3 months after stroke predicts long-term survival. Cerebrovasc Dis 2008, 25:423-429.

6. Lefkovits J, Davis SM, Rossiter SC, Kilpatrick CJ, Hopper JL, Green R, et al: Acute stroke outcome: effects of stroke type and risk factors. Aust N Z J Med 1992, 22:30-35.

7. Carod-Artal J, Egido JA, Gonzalez JL, Varela de SE: Quality of life among stroke survivors evaluated 1 year after stroke: experience of a stroke unit. Stroke 2000, 31:2995-3000.

8. Wyller TB, Holmen J, Laake P, Laake K: Correlates of subjective well-being in stroke patients. Stroke 1998, 29:363-367.

9. Hillen T, Davies S, Rudd AG, Kieselbach T, Wolfe CD: Self ratings of health predict functional outcome and recurrence free survival after stroke. J Epidemiol Community Health 2003, 57:960-966.

10. George LK, Landerman R: Health and subjective well-being: a replicated secondary data analysis. Int J Aging Hum Dev 1984, 19:133-156.

11. Kaplan G, Baron-Epel O: What lies behind the subjective evaluation of health status? Soc Sci Med 2003, 56:1669-1676.

12. Mavaddat N, Kinmonth AL, Sanderson S, Surtees P, Bingham S, Khaw KT: What determines Self-Rated Health (SRH)? A cross-sectional study of SF-36 health domains in the EPIC-Norfolk cohort. J Epidemiol Community Health 2011, 65:800-806.

13. Emmelin M, Weinehall L, Stegmayr B, Dahlgren L, Stenlund H, Wall S: Self-rated ill-health strengthens the effect of biomedical risk factors in predicting stroke, especially for men - an incident case referent study. J Hypertens 2003, 21:887-896.

14. Idler EL, Kasl SV: Self-ratings of health: do they also predict change in functional ability? I Gerontol B Psychol Sci Soc Sci 1995, 50:S344-S353.

15. Idler EL, Benyamini Y: Self-rated health and mortality: a review of twenty-seven community studies. J Health Soc Behav 1997, 38:21-37.

16. Darlington AS, Dippel DW, Ribbers GM, van Balen R, Passchier J, Busschbach JJ: Coping strategies as determinants of quality of life in stroke patients: a longitudinal study. Cerebrovasc Dis 2007, 23:401-407.

17. Teoh V, Sims J, Milgrom J: Psychosocial predictors of quality of life in a sample of community-dwelling stroke survivors: a longitudinal study. Top Stroke Rehabil 2009, 16:157-166.

18. Kim P, Warren S, Madill H, Hadley M: Quality of life of stroke survivors. Qual Life Res 1999, 8:293-301.

19. Singh-Manoux A, Martikainen P, Ferrie J, Zins M, Marmot M, Goldberg M: What does self rated health measure? Results from the British Whitehal II and French Gazel cohort studies. J Epidemiol Community Health 2006 60:364-372.

20. Haseli-Mashhadi N, Pan A, Ye X, Wang J, Qi Q, Liu Y, et al: Self-Rated Health in middle-aged and elderly Chinese: distribution, determinants and associations with cardio-metabolic risk factors. BMC Public Health 2009, 9:368.

21. Molarius A, Janson S: Self-rated health, chronic diseases, and symptoms among middle-aged and elderly men and women. J Clin Epidemiol 2002, 55:364-370.

22. Alves $L C$, Rodrigues $R N$ : [Determinants of self-rated health among elderly persons in Sao Paulo, Brazil]. Rev Panam Salud Publica 2005, 17:333-341.

23. Damián J, Pastor-Barriuso R, Valderrama-Gama E: Factors associated with self-rated health in older people living in institutions. BMC Geriatrics 2008, 8:5. do: 10.1186/1471-2318-8-5.

24. Brayne C, McCracken C, Matthews FE: Cohort profile: the Medical Research Council Cognitive Function and Ageing Study (CFAS). Int I Epidemiol 2006, 35:1140-1145

25. Elias P, Halstead K, Prandy K: CASOC: Computer-Assisted Standard Occupational Coding. London: HMSO; 1993.
26. Folstein MF, Folstein SE, McHugh PR: "Mini-mental state". A practical method for grading the cognitive state of patients for the clinician. J Psychiatr Res 1975, 12:189-198.

27. Benton AL, Hamsher K: Multilingual Aphasia Examination manual. lowa City: University of lowa; 1976.

28. Towfighi A, Markovic D, Ovbiagele B: Current national patterns of comorbid diabetes among acute ischemic stroke patients. Cerebrovasc Dis 2012, 33:411-418.

29. Otiniano ME, Du XL, Ottenbacher K, Markides KS: The effect of diabetes combined with stroke on disability, self-rated health, and mortality in older Mexican Americans: results from the Hispanic EPESE. Arch Phys Med Rehabil 2003, 84:725-730

30. Wee HL, Cheung YB, Li SC, Fong KY, Thumboo J: The impact of diabetes mellitus and other chronic medical conditions on health-related Quality of Life: is the whole greater than the sum of its parts? Health Qual Life Outcomes 2005, 3:2.

31. McFadden E, Luben R, Bingham S, Wareham N, Kinmonth AL, Khaw KT: Social inequalities in self-rated health by age: cross-sectional study of 22,457 middle-aged men and women. BMC Public Health 2008, 8:230.

32. Chang-Quan H, Xue-Mei Z, Bi-Rong D, Zhen-Chan L, Ji-Rong Y, Qing-Xiu L: Health status and risk for depression among the elderly: a meta-analysis of published literature. Age Ageing 2010, 39:23-30.

33. House A, Knapp P, Bamford J, Vail A: Mortality at 12 and 24 months after stroke may be associated with depressive symptoms at 1 month. Stroke 2001, 32:696-701.

34. Putman K, De WL, Schoonacker M, Baert I, Beyens H, Brinkmann N, et al: Effect of socioeconomic status on functional and motor recovery after stroke: a European multicentre study. J Neurol Neurosurg Psychiatry 2007, 78:593-599.

35. Naess H, Lunde L, Brogger J, Waje-Andreassen U: Depression predicts unfavourable functional outcome and higher mortality in stroke patients: the Bergen Stroke Study. Acta Neurol Scand Suppl 2010:34-38.

36. Aslanyan S, Weir CJ, Lees KR, Reid JL, Mclnnes GT: Effect of area-based deprivation on the severity, subtype, and outcome of ischemic stroke. Stroke 2003, 34:2623-2628.

37. Cott CA, Gignac MA, Badley EM: Determinants of self rated health for Canadians with chronic disease and disability. J Epidemiol Community Health 1999, 53:731-736.

38. Ahlsio B, Britton M, Murray $\mathrm{V}$, Theorell T: Disablement and quality of life after stroke. Stroke 1984, 15:886-890.

39. Almborg AH, Ulander $\mathrm{K}$, Thulin A, Berg S: Discharged after stroke - important factors for health-related quality of life. J Clin Nurs 2010, 19:2196-2206.

40. Astrom M, Asplund $K$, Astrom T: Psychosocial function and life satisfaction after stroke. Stroke 1992, 23:527-531.

41. King RB: Quality of life after stroke. Stroke 1996, 27:1467-1472.

42. Mayo NE, Wood-Dauphinee S, Cote R, Durcan L, Carlton J: Activity, participation, and quality of life 6 months poststroke. Arch Phys Med Rehabil 2002, 83:1035-1042.

43. Barnsley L, McCluskey A, Middleton S: What people say about travelling outdoors after their stroke: a qualitative study. Aust Occup Ther J 2012, 59:71-78.

44. Logan PA, Leighton MP, Walker MF, Armstrong A, Gladman JRF, Sach TH, et al: A multi-centre randomised controlled trial of rehabilitation aimed at improving outdoor mobility for people after stroke: study protocol for a randomised controlled trial. Trials 2012, 13:86

45. McCluskey A, Ada L, Middleton S, Kelly P, Goodall S, Grimshaw JM, et al: Improving quality of life by increasing outings after stroke: study protocol for the Out-and-About trial. Int J Stroke 2013, 8(1):54-58.

46. Coughlan AK, Humphrey M: Presenile stroke: long-term outcome for patients and their families. Rheumatol Rehabil 1982, 21:115-122.

47. Young J, Forster A: Rehabilitation after stroke. BMJ 2007, 334:86-90.

48. Horgan F, McGee H, Hickey A, Whitford DL, Murphy S, Royston M, et al: From prevention to nursing home care: a comprehensive national audit of stroke care. Cerebrovasc Dis 2011, 32:385-392.

\section{doi:10.1186/1471-2318-13-85}

Cite this article as: Mavaddat et al.: What determines the self-rated health of older individuals with stroke compared to other older individuals? A cross-sectional analysis of the Medical Research Council Cognitive Function and Aging Study. BMC Geriatrics 2013 13:85. 